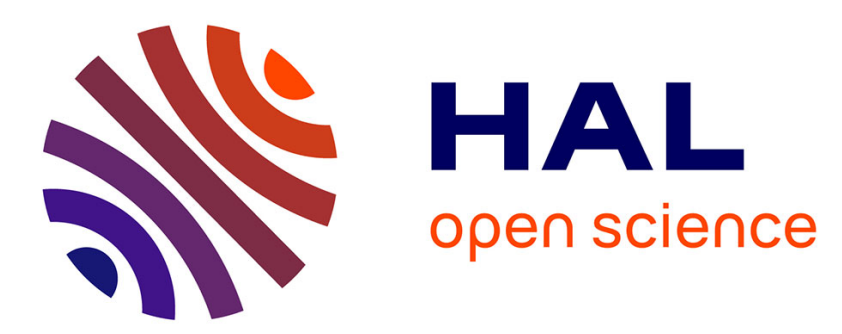

\title{
Gold and gold-graphene used as cathodic interfaces for scission of carbon-halogen bonds. Application to the building of anthraquinone-Au electrodes
}

\author{
Jacques Simonet, Viatcheslav Jouikov
}

\section{To cite this version:}

Jacques Simonet, Viatcheslav Jouikov. Gold and gold-graphene used as cathodic interfaces for scission of carbon-halogen bonds. Application to the building of anthraquinone-Au electrodes. Electrochemistry Communications, 2014, 40, pp.58-62. 10.1016/j.elecom.2013.12.024 . hal-01057935

HAL Id: hal-01057935

https://hal-univ-rennes1.archives-ouvertes.fr/hal-01057935

Submitted on 25 Aug 2014

HAL is a multi-disciplinary open access archive for the deposit and dissemination of scientific research documents, whether they are published or not. The documents may come from teaching and research institutions in France or abroad, or from public or private research centers.
L'archive ouverte pluridisciplinaire HAL, est destinée au dépôt et à la diffusion de documents scientifiques de niveau recherche, publiés ou non, émanant des établissements d'enseignement et de recherche français ou étrangers, des laboratoires publics ou privés. 


\title{
Gold and gold-graphene used as cathodic interfaces for scission of carbon-halogen bonds. Application to the building of anthraquinone-Au electrodes.
}

\author{
Jacques Simonet $^{\mathrm{a} *}$ and Viatcheslav Jouikov ${ }^{\mathrm{b}}$ \\ a) Laboratoire MaSCE, UMR 6226, Université de Rennes 1, Campus de Beaulieu, 35042 \\ Rennes Cedex, France. \\ b) CPM, UMR 6226, Université de Rennes 1, Campus de Beaulieu, 35042 Rennes Cedex, \\ France.
}

\begin{abstract}
Gold (smooth or covered with a thin layer of graphene) is an efficient free-radical scavenger when used as cathode material. This first work points out the immobilization of anthraquinone (AQ) in organic polar solvents containing tetraalkylammonium salts. It appears that $\mathrm{Au}$ and graphene, when negatively polarized $(\mathrm{E}>-1.0 \mathrm{~V}$ vs. $\mathrm{Ag} / \mathrm{AgCl}$ ), may react towards 2bromomethylantraquinone (AQ- $\left.\mathrm{CH}_{2}-\mathrm{Br}\right)$ in different ways: with $\mathrm{Au}$, a fast adsorption followed by one-electron transfer leads to a robust radical modification of the interface, whereas the presence of graphene permits the formation of a benzyl-type radical readily trapped by the graphene layer. Two different redox stable electrodes are thus produced. Additionally, stability of gold-graphene-AQ electrodes could be successfully tested in aqueous buffered solutions.
\end{abstract}




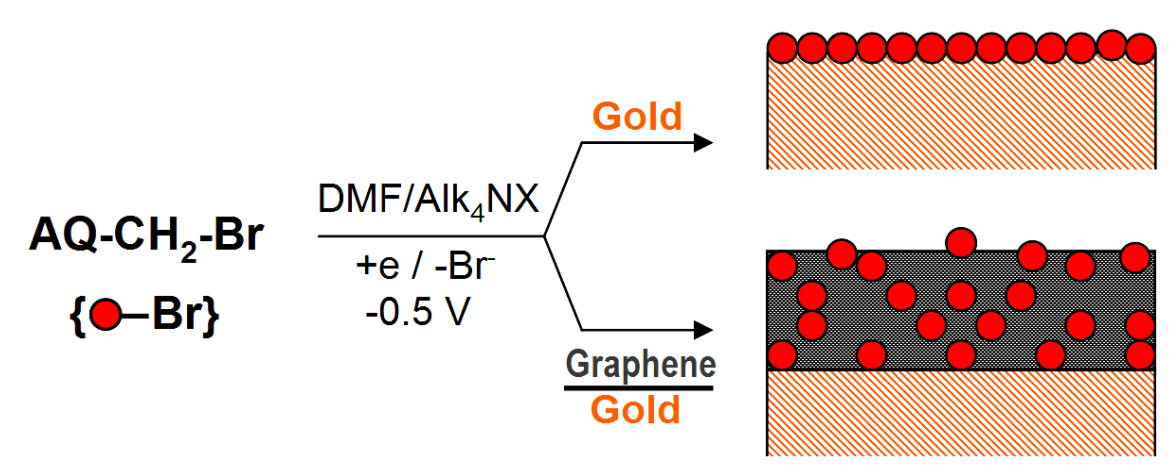

Key Words: Graphene; 2-Bromomethylanthraquinone; Anthraquinone electrodes. Graphenegold interface; Gold redox surfaces.

Corresponding author: Tel.: +33-23236292; Fax: + 33-23236732

E-mail address: jacques.simonet@univ-rennes1.fr

\section{Introduction}

In research of new solid electrodes for achieving specific reactions, carbon and platinum electrodes are classically employed [1]. For building new surfaces by means of free radical addition, the electrocatalytic reduction of alkyl halides (generation of alkyl radicals) was achieved at carbons modified by thin deposits of palladium, silver or copper. In the field of aryl radicals, the reductive scission of chemical bonds (chemical or electrochemical, essentially with aryl diazonium salts) permits immobilization of aromatic moieties onto carbons and graphite $[2,3]$.

Until now, the use of gold for functional modifications is limited. However, it appears that an interesting behavior of gold lies in its propensity to undergo strong adsorption of organic molecules. Thus, it is known that linear alkanes adsorb at gold with binding energy of 14-81 $\mathrm{kJ} \mathrm{mol}^{-1}$ [4]. Concerning organic halides, a metastable adsorption of MeI at $\mathrm{Au}(100)$ [5] occurs (in first layer) with the C-I bonds parallel to the surface, practically without decomposition. A pre-reaction of iodoalkanes with gold was also reported, creating Au-C and Au-I bonds [6]. Very recently [7], such behavior of Au towards RIs was used to develop a 
new cathodic reactivity of gold for building stable organic layers robustly immobilized at the metal interface.

At this stage, the reactivity of interfaces gold/carbons (the latter in the form of graphites, fullerenes, and graphenes) deserves quite certainly beto be considered. The main goal of this communication is to focus a new light on gold as a cathode material. Moreover, the interest for gold is increased if it is associated with a graphene thin layer at its surface and applied to the cathodic cleavage of activated organic bromides, in particular from the family of benzyl bromides.

The present preliminary study focuses on the behavior of 2-bromomethylanthraquinone (BMAQ) and underlines comparing two kinds of grafting AQ moieties onto smooth gold and gold-graphene. As is shown hereafter, these two different AQ redox surfaces presented here differ quite dramatically from those already reported concerning both the mode of grafting and the nature of the resulting interfaces [8-13]. This work points out the use of aqueous and non-aqueous systems, stability of the deposits, and the totally unexpected interesting catalytic synergy \{graphene-gold \} that could be developed in the scission of carbon-halogen bonds at high potentials for generating and trapping free radicals within very thin layers.

\section{Experimental}

\subsection{Electrochemical procedure; salts and solvents}

Solutions of tetra- $n$-butylammonium and tetramethylammonium tetrafluoroborates $\left(\mathrm{TMABF}_{4}\right.$ and $\left.\mathrm{TBABF}_{4}\right)$ in dimethylformamide (DMF) were used. The supporting salt concentration was $0.1 \mathrm{M}$. It is worth mentioning that the procedures given hereafter did not need extremely dry solutions (water content $<1000 \mathrm{ppm}$ ). All electrochemical experiments were performed under inert atmosphere with bubbling of dry argon through the solution. The potentials are given versus aqueous $\mathrm{Ag} / \mathrm{AgCl} / \mathrm{KCl}_{\text {(sat) }}$. The electrochemical instrumentation has been previously described [7].

\subsection{Working electrodes}

The electrodes used for voltammetry had apparent surface areas of $0.8 \mathrm{~mm}^{2}$. Before being used as electrode materials, gold surfaces were carefully polished with silicon carbide paper (Struers 500 and 1200) or with Norton polishing paper (type 02 and 03) and rinsed with water, alcohol and acetone. Finally, each electrode was dried with a hot air flow during about $30 \mathrm{~s}$. 
Coulometric measurements and electrolyses of alkyl iodides reported in this work were carried out using three-electrode cells with a total catholyte volume of 5 to $10 \mathrm{~mL}$. A fritted glass separated the two compartments.

Gold electrodes were prepared by sealing a gold wire in a glass tube with a non-electroactive glue (Torrseal, Varian), non soluble in DMF. Graphene was purchased from XG Sciences as XGnP Graphene Nanoplatelets-Grade C typically consisting of submicron platelets (particle diameter $<2 \mu \mathrm{m}$, with thickness of a few $\mathrm{nm}$ ). The average surface is of the order of $750 \mathrm{~m}^{2} / \mathrm{g}$ and TEM images permit one to detect almost transparent platelets. Oxygen content was $<2 \mathrm{wt} \%$ while that of carbon $>98.0 \mathrm{wt} \%$. The deposition of graphene onto gold was achieved by firmly rubbing the metal electrode onto a glassy cardboard on which was dispersed a few mg of graphene. The electrode is ready to use when a transparent carbon film is covering the gold electrode. The thickness of the graphene film is estimated to be less than $1 \mu \mathrm{m}$.

\subsection{Organic materials}

2-Bromomethylanthraquinone (BMAQ) solvents, and supporting salts were purchased from Aldrich.

\section{Results}

The BMAQ was reduced under two fundamentally different conditions: (i) at smooth gold electrodes and (ii) at smooth gold covered by a very thin graphene layer. As mentioned above, the interest of graphene is both in accelerating catalytic scission of $\mathrm{C}-\mathrm{Br}$ bond by gold and in trapping (to a large extent) $\mathrm{AQ}-\mathrm{CH}_{2}{ }^{\bullet}$ radicals formed in the electrochemical process that takes place at the interface.

The reduction at gold $\left(\mathrm{DMF} / 0.1 \mathrm{M} \mathrm{TBABF}_{4}\right)$ is displayed in Figure 1, curve A1. During the first scan, irreversible step $a\left(\mathrm{E}_{\mathrm{p}}=-0.58 \mathrm{~V}\right)$ is assigned to the reduction of the C-Br bond adsorbed at Au BMAQ. Two following steps correspond to the reversible reduction of the AQ moiety to give AQ radical anion and dianion $\left(E_{p}=-0.82\right.$ and $-1.44 \mathrm{~V}$, respectively). In the second scan, the layer formed by grafting of the adsorbed BMAQ inhibits electron transfer at $a$ and one observes then a large increase of the reversible reduction of free BMAQ possibly provoked by the redox catalysis brought by the AQ group. This assumption is confirmed by voltammetry of the modified surface obtained by dipping the Au electrode in a solution of BMAQ in DMF (with following rinsing and sonication) that shows the two steps of AQ. After holding the potential at the level of step $a$ (or by fixed potential electrolysis at $0.6 \mathrm{~V}$ passing $0.3 \times 10^{-3} \mathrm{C}$ ), the redox behavior of the modified Au surface is shown in curve A2, Figure 1; 
steps I and II are assigned to the reversible formation of $\mathrm{AQ}^{\bullet-}$ and $\mathrm{AQ}^{=}$(with the main step I depicting a two-electron transition $\left(E_{\text {red }}=-0.75 \mathrm{~V}\right.$ and $\left.E_{\mathrm{ox}}=-0.72 \mathrm{~V}\right)$. Repetitive scans show the robustness of the grafting. The prominence of the two-electron step is partly due to traces of moisture in the electrolyte, but essentially owing to Hofmann degradation (protonation of the dianion by the salt producing residual acidity at the surface during the oxidation scans). On the basis of the two-electron step (main reduction and oxidation), the superficial concentration of AQ could be calculated: $\Gamma_{\mathrm{AQ}}=(4.3 \pm 0.2) \times 10^{-10} \mathrm{~mol} \mathrm{~cm}^{-2}$. Those values are very close to those reported for adsorbed long-chain alkanethiols bearing ferrocene and tetrathiafulvalenes $[14,15]$, suggesting that almost pure grafting processes occur (therefore implying a quasiabsence of multilayers that might be due to non-selectivity of the addition of free radicals).

When BMAQ reduction was carried out at gold electrodes whose surfaces were doped with a very thin layer of graphene, a quite different grafting process was observed, with the immobilization of the AQ moiety onto the whole active surface (including graphene). First of all, the reduction of BMAQ takes place at a potential much less negative than that observed at bare $\mathrm{Au}$ (peak $b, \mathrm{E}_{\mathrm{p}}=-0.40 \mathrm{~V}$ ) along with a minor step $a$ (Figure $\left.1, \mathrm{~B} 1\right)$ suggesting that a double activation may occur, one by graphene, the other by Au. It is expected that the reduction at the level of $b$ corresponds to the catalytic reduction of the organic substrate and to the formation of a free radical (reaction 1, Scheme 1) at the graphene-Au interface (quite probably according to a synergistic effect) followed by a fast addition of this radical to graphene, acting as a radical trap. Consequently, neither inhibition of the $\mathrm{Au}$ surface described above nor the catalytic process induced by the grafted AQ layer takes place. Grafted AQ moieties are then principally immobilized within the carbon layer in quite high concentration and the catalytic efficiency of this new 3D AQ electrode may predict interesting perspectives in terms of catalysis. The coverage of the electrode by AQ appears robust, and currents in the course of repetitive scans stabilize quite fast: in $\mathrm{TMABF}_{4}$, in the absence of a large protonation by the salt, two sharp reversible steps are observed (Curve D, Figure 2) $\mathrm{E}_{\text {red }}^{\mathrm{I}}$ $=-0.92 \mathrm{~V}, \mathrm{E}_{\text {ox }}^{\mathrm{I}}=-0.82 \mathrm{~V}$ and $\mathrm{E}_{\text {red }}^{\mathrm{II}}=-1.29 \mathrm{~V}, \mathrm{E}_{\text {ox }}^{\mathrm{II}}=-1.20 \mathrm{~V}$. Current integration of the first one-electron peak (half-width $130 \mathrm{mV}$ ) suggests that the apparent superficial AQ concentration is quite large, $4.0 \times 10^{-8} \mathrm{~mol} \mathrm{~cm}^{-2}$, which implies that the graphene layer incorporates about 50 to 100 equivalents of AQ immobilized in a monolayer at smooth gold.

The robustness of AQ anchoring onto Au-graphene was checked in buffered aqueous solutions (Figure 2, pH 5.5 and 10). Only large reversible two-electron steps could be seenwith a small shift between cathodic and anodic steps $\left(E_{r e d}-E_{o x}=100 \mathrm{mV}\right)$ assigned to the motion of species within the graphene layers. The superficial concentration of immobilized 
AQ moieties was found to be $\Gamma_{\mathrm{AQ}}=(3.0 \pm 0.5) \times 10^{-8} \mathrm{~mol} \mathrm{~cm}^{-2}$ and is therefore quite close to those found above. The peak currents are linear with the scan rate $v$.

Surface reflectance FTIR spectroscopy (Figure 2E) of the modified interfaces attests to the presence of the AQ moiety by its characteristic amide I and II bands. EIS measurements (Figure 2F) reveal an inhomogeneity of the immobilized graphene-anthraquinone layer: the zones with charge transfer resistance $\mathrm{R}_{\mathrm{CT}}$ of $520 \Omega, 9.1$ and $164 \mathrm{k} \Omega$, related to three capacitive elements with different time constants, are distinctly seen in a Bode phase angle plot. Supposedly, their formation is governed by complex interplay of the grafting kinetics versus diffusion and steric demand, leading to three kinds of sub-structures within the immobilized 3D layer. Without graphene, the anthraquinone layer deposited at gold does not create substantial impedance to the charge transfer so only a diffusional low-frequency branch is revealed at these frequencies (Figure 2E, 2-3).

\section{Conclusion}

The present work underlines that anthraquinone can be immobilized under a very simple and efficient procedure, on gold either bare or doped by thin graphene layers. The chosen method is based on cathodic scission of the $\mathrm{C}$-Br bond of in 2-bromomethylanthraquinone, and it appears that the grafting efficiency stems from the catalytic synergy brought on by both $\mathrm{Au}$ and graphene. At smooth gold, almost ideal mono-layers are obtained while coverage of gold with graphene yields 3D AQ-electrodes. The great interest of graphene specifically associated to gold arises from the addition of large amounts of radicals onto this material that remains conducting. This permits one to conceive new redox interfaces with graphene-based layers easily modifiable by a large palette of functions, that are could appear very useful for achieving many kinds of catalysis. 


\section{References}

[1] D.G. Peters, in: H. Lund, O. Hammerich (Eds.), Organic Electrochemistry, M.M. Dekker, New York, Basel, 2001, p. 341.

[2] D. Bélanger, J. Pinson, Chem. Soc. Rev. 40 (2011) 3995.

[3] F. Hui, J.-M. Noël, P. Poizot, P. Hapiot, J. Simonet, Langmuir 27 (2011) 5119

[4] R. J. Baxter, G. Teobaldi, F. Zerbetto, Langmuir, 19 (2003), 7335.

[5] M. X. Yang, S. K. Jo, A. Paul, L. Avila, B. E. Bent, K. Nishikida, Surface Science, 325 (1995) 102.

[6] M. Hirayama, W. R. Caseri, U. W. Suter, J. Colloid Interface Science, 202 (1998) 167.

[7] J. Simonet, V. Jouikov, Electrochem. Comm. (2013), http://dx.doi.org/10.1016/j.elecom.2013.11.003.

[8] M. A. Ghanem, I. Kocak, A. Al-Mayouf, M. Alhoham, P. N. Barlett, Electrochim. Acta, 68 (2012) 74.

[9] K. Vaik, U. Mäeorg, F.C. Maschion, G. Maia, D. J. Schiffrin, Electrochim. Acta, 50 (2005) 5126.

[10] Q. Li, C. Bachelor-McAuley, N. S. Lawrence, R. S. Harshorne, R. G. Compton, New J. Chem., 35 (2011) 2462.

[11] V. Jouikov, J. Simonet, Electrochem. Comm., 27 (2013) 180.

[12] M.A.Ghanenn, I. Kocak, A.Al.Mayouf, P. N. Bartlett, Electreochem. Comm., 34 (2013) 258.

[13] M.Kallupere, M. Marandi, K. Sanmelselg, H.A. Menezes, G. Maia, K. Tammeveski, Electrochem. Comm., 11 (2009) 405.

[14] M. Frasconi, A. D'Annibale, G. Favero, F. Mazzei, S. Rantucci, T. Ferri, Langmuir, 25 206 (2009) 12937.

[15] Y. Yokota, A. Miyazaki, F. Fukui, T. Enoki, J. Phys. Chem. B, 110 (2006) 20401. 


\section{$\underline{\text { Figure caption }}$}

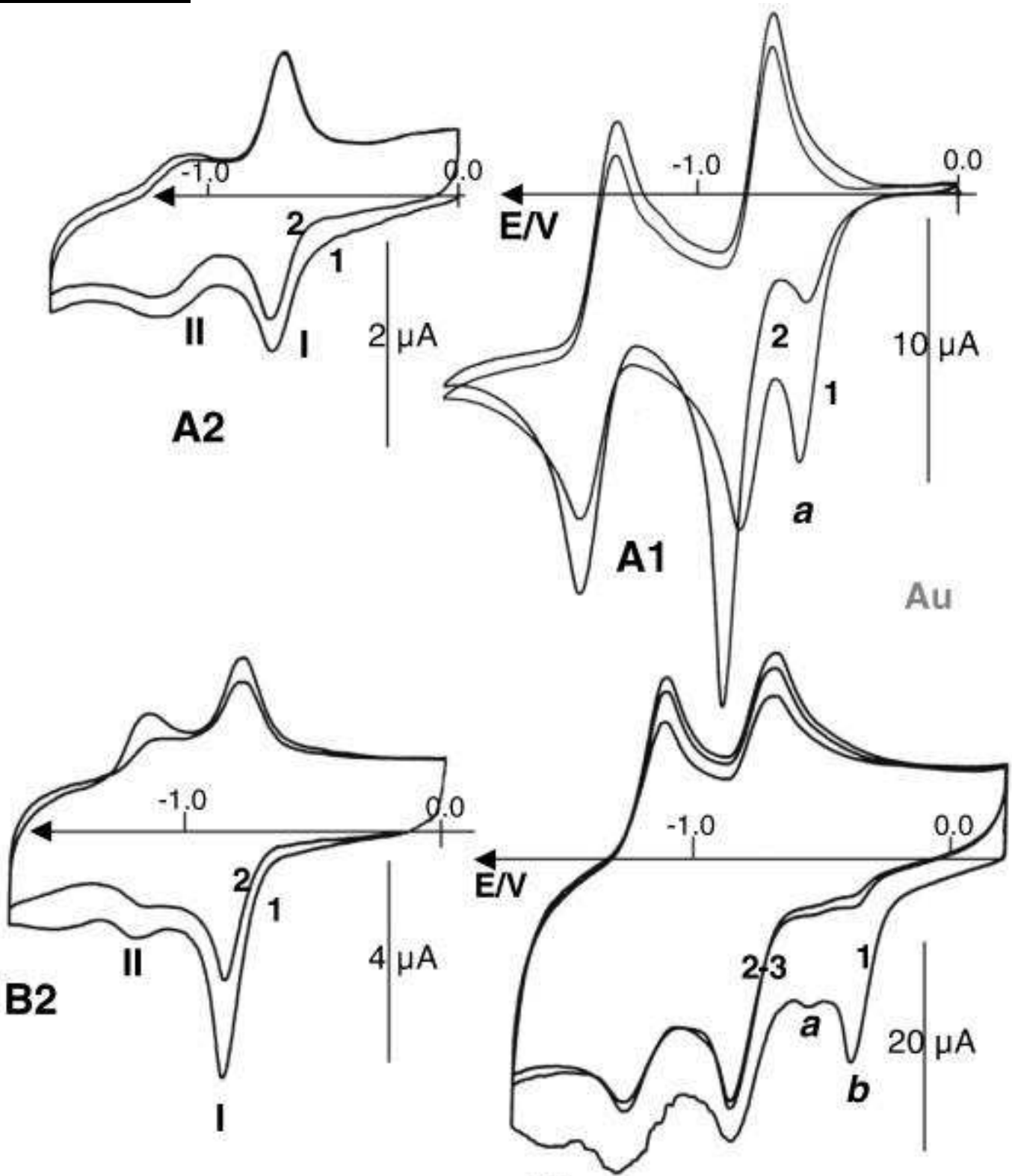

B1

\section{$\mathrm{Au} / \mathrm{GR}$}

Figure 1

(A1) Voltammetry (two first scans) of BMAQ $\left(8.9 \times 10^{-3} \mathrm{~mol} \mathrm{~L}^{-1}\right.$ in DMF/0.1M TBABF 4 ) at stationary gold cathode (area: $0.8 \mathrm{~mm}^{2}$ ). Scan rate $50 \mathrm{mV} \mathrm{s}^{-1}$.

(A2) Response of the deposit (in DMF/0.1M TBABF 4 ) at gold after the potential hold at -0.6 $\mathrm{V}$ for $1 \mathrm{~min}$. Scan rate $200 \mathrm{mV} \mathrm{s}^{-1}$.

(B1) Voltammetry of BMAQ $\left(7.8 \times 10^{-3} \mathrm{~mol} \mathrm{~L}^{-1}\right.$ in $\left.\mathrm{DMF} / 0.1 \mathrm{M} \mathrm{TBABF} 4\right)$ at gold/graphene.

(B2) Response after the potential hold at $-0.3 \mathrm{~V}$. 

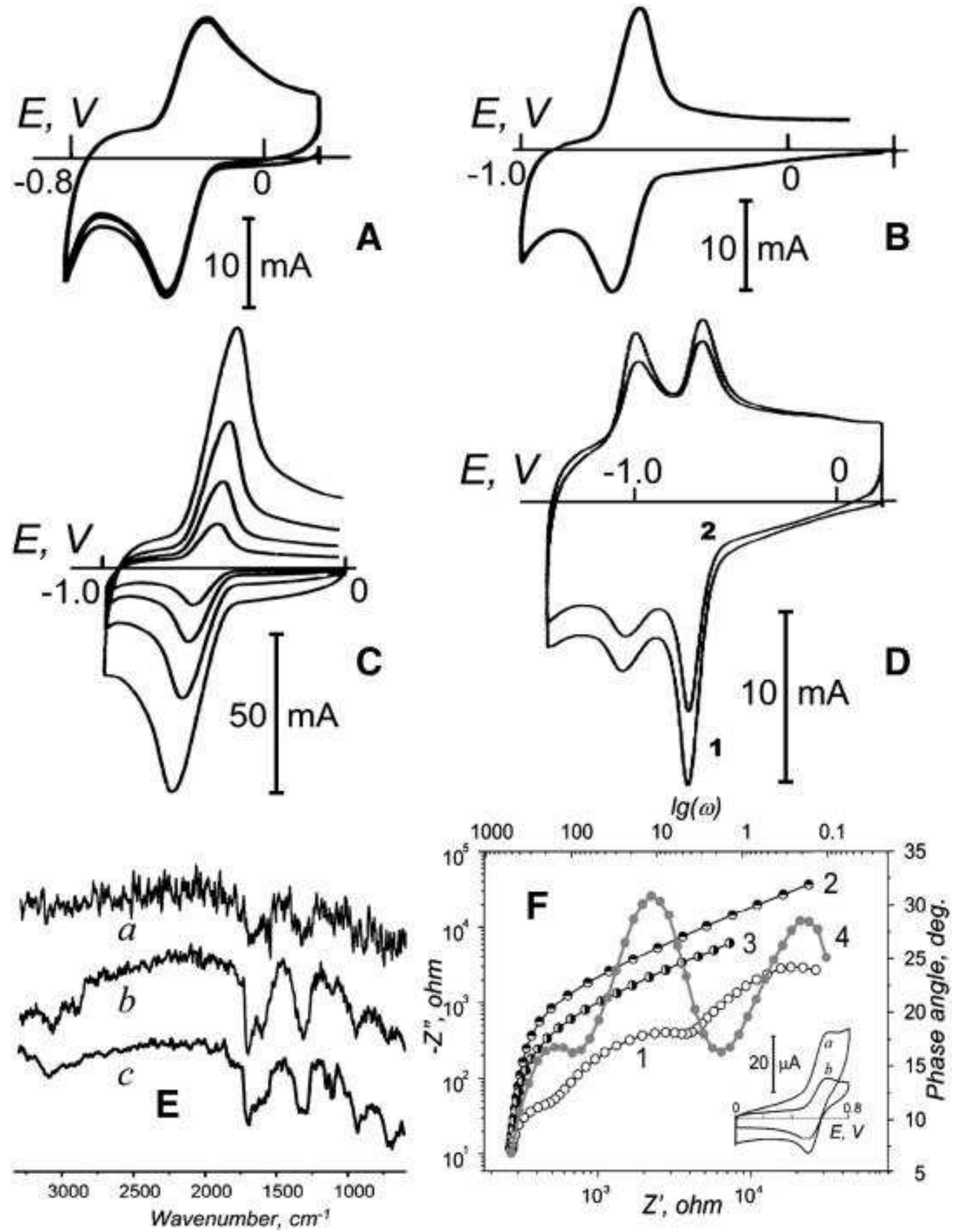

$\underline{\text { Figure } 2}$

Deposition of AQ by fixed potential electrolysis (-0.5 V). Au/graphene working electrode. Amount of electricity: $0.6 \times 10^{-3} \mathrm{C}$. In (A) and (B) are shown the responses $\left(50 \mathrm{mV} \mathrm{s}^{-1}\right)$ in buffered solutions ( $\mathrm{pH} 5.5$ and 10.0 respectively). In (C), responses ( $\mathrm{pH} 10)$ at scan rates from 20 to $200 \mathrm{mV} \mathrm{s}^{-1}$. (D) Cycling of AQ deposited at Au/graphene in TMABF $/$ DMF $\left(50 \mathrm{mV} \mathrm{s}^{-}\right.$ $\left.{ }^{1}\right)$. (E) Reflectance FTIR spectra of: (a) Au modified with AQ, (b) Pt-graphene-AQ, (c) Pdgraphene-AQ. 3100-2900 $\mathrm{cm}^{-1}$ ( $v_{\mathrm{C}-\mathrm{H}}$ of $\mathrm{CH}_{2}$, phenyl and edge $\mathrm{C}-\mathrm{H}$ of graphene), 1710-1610 $\mathrm{cm}^{-1}$ and $1330-1300 \mathrm{~cm}^{-1}$ (quinone $v_{\mathrm{C}=\mathrm{O}}, v_{\mathrm{C}=\mathrm{C}}$ and $v_{\mathrm{C}-\mathrm{C}}$ ), 930, $700 \mathrm{~cm}^{-1} \delta_{\mathrm{C}-\mathrm{H}}$. (F) Niquist (1-3) and Bode (4) plots of the reduction of chloranil in acetonitrile/0.1 $\mathrm{M} \mathrm{Bu}_{4} \mathrm{NPF}_{6}$ at: (1) Goldgraphene electrode modified with AQ; (2) Au electrode modified with AQ; (3) Bare Au electrode. $\mathrm{E}=-0.18 \mathrm{~V}, \Delta \mathrm{E}=10 \mathrm{mV}$. Frequency range: from $1 \mathrm{MHz}$ to $0.01 \mathrm{~Hz}$. 


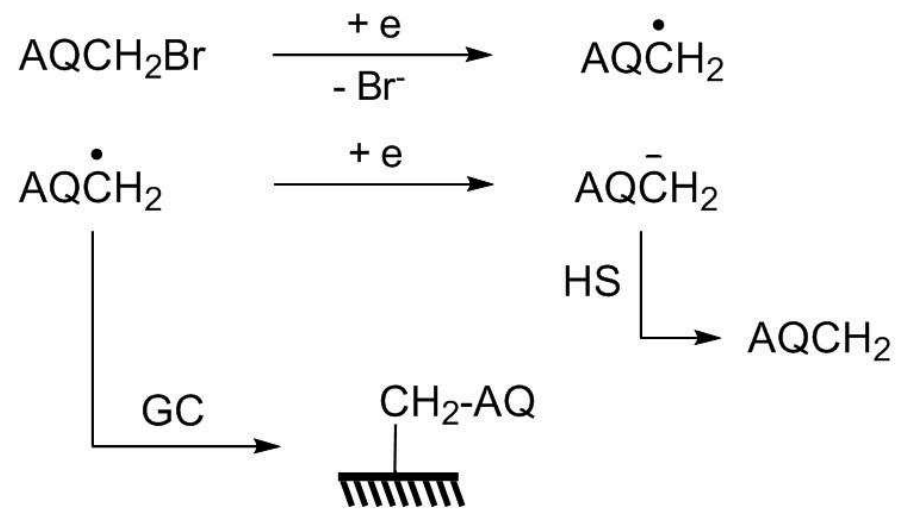

With

$$
\mathrm{AQ}+\mathrm{e} \stackrel{\text { I }}{\rightleftarrows} \mathrm{AQ}^{-}+\mathrm{e} \stackrel{\text { II }}{\rightleftarrows} \mathrm{AQ}^{=}
$$

At gold:

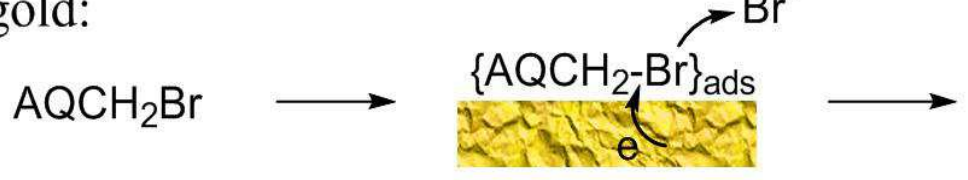

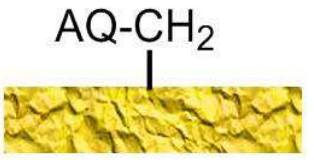

At gold-graphene: $\quad \mathrm{AQCH}_{2} \mathrm{Br}$
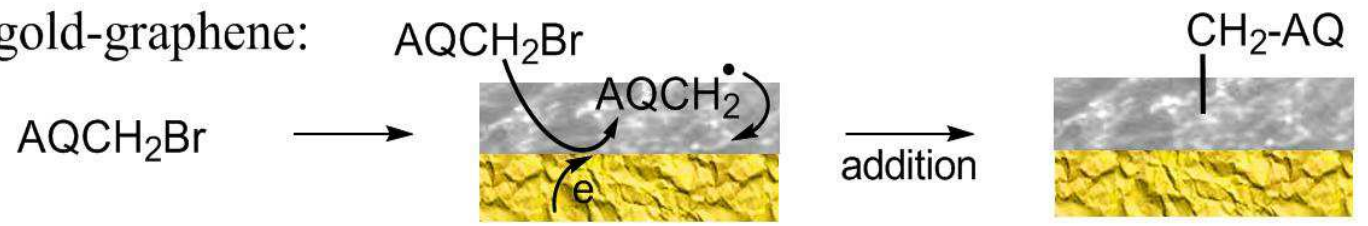

Scheme 1 